\title{
STAKEHOLDER OPINION-BASED COMPARISON OF LIFE CYCLE ENVIRONMENTAL IMPACTS OF ELECTRICITY GENERATION IN TURKEY WITH SELECTED EUROPEAN COUNTRIES
}

\author{
Fehmi Görkem ÜÇTUĞ * \\ School of Chemical Engineering and Analytical Sciences,Sustainable Industrial Systems Research Group, \\ The University of Manchester, United Kingdom
}

\begin{abstract}
The life cycle environmental impacts of electricity generation in Turkey were compared to those of Denmark, France, and Poland. The reason for selecting these particular countries for benchmarking was the fact that electricity generation in these countries is dominated mostly by a single source, that is wind, nuclear, and coal, respectively. OpenLCA ${ }^{\mathrm{TM}}$ software and European Life Cycle Database were used, CML2001 method was employed. The life cycle analysis approach was from cradle to grave. The environmental impact criteria which were studied were acidification, global warming potential, depletion of abiotic resources - elements, depletion of abiotic resources - fossil fuels, eutrophication, freshwater aquatic ecotoxicity, human toxicity, marine aquatic ecotoxicity, ozone layer depletion, photochemical oxidation, and terrestrial ecotoxicity. In addition to comparing the four countries in terms of these individual impacts, the overall environmental impact scores for all countries were calculated, once with equal weights for all impacts and once with weights which were determined by acquiring the stakeholder opinions via an online questionnaire. In both cases, Poland turned out to have the highest environmental impact due to the high share coal in the electricity mix, and Turkey came second after Poland. Equal-weightanalysis returned Denmark as the country with the cleanest electricity generation infrastructure whereas stakeholder-weightanalysis results showed that it was France who had the lowest environmental impact. This result was attributed to the high weight of global warming potential and France's nuclear-energy-based electricity generation system has a very low global warming potential when compared to other three countries. It was concluded that the prospective addition of nuclear energy, solar energy, and clean coal technologies into Turkey's electricity mix shall reduce the overall environmental impact of electricity generation in Turkey significantly.
\end{abstract}

Key words: Electricity generation; Environmental impact; Life cycle analysis; Turkey

\section{INTRODUCTION}

The continuous rising of the world population, accompanied by the depletion of resources and climate change have all contributed to the increase of attention on sustainable development. The energy sector is a major contributor to economic and industrial activities and also all basic human needs are based on energy. Therefore, achieving sustainable development cannot be realized without improving the sustainability of energy generation and supply. However, the conversion and consumption of energy lead to several different environmental impacts [1]. For instance, it is estimated that approximately $80 \%$ of global greenhouse gas emissions arises from energy-related processes, and $75 \%$ of that comes from electricity generation [2]. Recently, representatives of 185 countries across the world attended the 2015 United Nations Climate Change Conference, which was held in Paris [3]. Decisions have then been made by all world countries concerning actions about climate change, especially those related to energy generation [4].

While the Paris Conference was gathered due to concerns that mainly circulate around global warming, there are several important environmental impacts associated with electricity generation, transmission, and distribution. People whose analyze such impacts usually focus on the actual energy generation processes on site, however the situation can only be realistically pictured if we consider all 
the stages of electricity supply processes. These stages would include the extraction of the energy source (does not apply to renewable sources such as wind or solar), the transportation of materials, the construction of the power plant, the operation of the power plant, and finally the decommissioning of the power plant once its useful life comes to an end. This approach is called "cradle-to-grave analysis" and it is the building block of life cycle assessment (LCA) [5].

In this particular study, the environmental impacts of electricity generation in Turkey and selected European countries were compared by employing LCA methodology. Instead of comparing technologies one by one, the environmental impacts created by the overall electricity supply mix of the countries were acquired. Comparison was realized in two parts: Firstly, the individual impacts of each country were compared to one another and then the relative scores were discussed in the light of the electricity mixes and quality of the sources and technologies used in each country. Secondly, weights were assigned to the environmental impacts by obtaining stakeholder opinions and the overall performances of each country were calculated. Detailed explanation of the method can be found in section 3 .

\section{LITERATURE REVIEW}

As indicated above, studies that focus on individual energy technologies or sources are not within the scope of this study and therefore such papers/reports were not reviewed. However, studies that focus on economic and/or social aspects of electricity generation in addition to environmental impacts were taken into consideration. Santoyo-Castelazo et al. studied the LCA of electricity generation in Mexico [1]. They studied the following life-cycle stages: extraction of fuels and raw materials, processing and transportation of fuels; manufacture and construction of infrastructure; operation of power plants to generate electricity; construction and decommissioning of power plants; and waste disposal. They used GaBi as LCA software and chose CML2001 method. Brizmohun et al. analyzed the LCA of electricity generation in Mauritius [6]. They used SimaPro7 software and CML2001 method, and gathered data about the following environmental impacts: global warming potential (GWP), abiotic depletion potential (ADP), acidification potential (AP), eutrophication potential (EP), human toxicity potential (HTP), freshwater aquatic ecotoxicity potential (FAETP), marine aquatic ecotoxicity potential (MAETP), ozone layer depletion (ODP), photochemical oxidants creation potential (POCP) and terrestrial ecotoxicity potential (TETP). Instead of a cradle-to-grave approach, they preferred a "cradle-to-consumer" framework, thereby neglecting the decommissioning stage in their calculations. Stamford and Azapagic assessed the life cycle sustainability of different electricity scenarios for the United Kingdom, extending to 2070 [7]. The scenarios included the main technologies relevant to the country, which are nuclear, gas, coal with and without carbon capture and storage, wind, solar photovoltaics and biomass. Three levels of decarbonization were considered and the implications were assessed for techno-economic, environmental and social impacts on a life cycle basis. They defined 12 economic indicators, 10 environmental indicators, and 14 social indicators. The environmental indicators, which is the only indicator category that falls within the scope of this particular study, were recyclability of input materials, freshwater eco-toxicity potential, marine eco-toxicity potential, global warming potential (GHG emissions), ozone depletion potential, acidification potential, eutrophication potential, photochemical smog creation potential, land occupation, and terrestrial eco-toxicity potential. May and Brennan performed the sustainability assessment of electricity generation in Australia [8]. They analyzed some rather uncommon environmental impacts such as exergy depletion, exergy destruction, and particulates as well as commonly preferred ones such as climate change, acidification, eutrophication, ozone layer depletion, and toxicity. Kannan et al. studied the case of power generation in Singapore [9]. However, rather than a performing a full-scale environmental impact analysis, they mainly focused on greenhouse gas emissions. Gujba et al. looked into the implications of the energy policy in Nigeria and presented the life cycle environmental and economic analysis of the electricity sector in the future [10]. They used GEMIS4.3 and SimaPro6 software and 
databases to model the system, and considered four different time-periods: base-year (2003), 2010, 2020, and 2030. The impacts were calculated by employing CML2001 method.

As far as the studies involving Turkey are concerned, three studies by Atilgan and Azapagic were found to be worth analyzing deeper. In their first paper, they analyzed the life cycle impact assessment of fossil fuels in Turkey [11]. The scope of the study was from cradle to grave, comprising extraction, processing, and transportation of the fuels, their combustion to generate electricity in power plants and plant construction and decommissioning at the end of their lifetime. The environmental impacts were calculated by using GEMIS 4.8 and GaBi v.6 software packages and CML2001 methodology. In the second paper, they studied the life cycle environmental impacts of renewable energy systems in Turkey [12]. The paper's scope was limited to large and small reservoir hydroelectricity power plants, run-of-river hydroelectricity power plants, wind, and geothermal power plants. The year 2010 was chosen as the time reference; therefore information regarding solar energy was not present in the paper. GaBi software and CML2001 methodology were used. In the last paper of the trilogy Atilgan and Azapagic performed a very detailed life cycle assessment of electricity generation in Turkey, in which they calculated 11 environmental, 3 economic and 6 social indicators associated with electricity generation in Turkey [13]. They found that geothermal energy is the best option from an environmental point of view; however it has a relatively high cost.

This particular paper differs from previous studies in two ways: Firstly, this paper focuses on relating the individual energy mixes of the countries to their overall electricity generation life cycle environmental impact scores. The attribution was not performed quantitatively, as it will be explained in the following section, a qualitative approach was employed. Secondly, and more importantly, the overall LCA scores for each country was calculated based on stakeholder opinion. The latter feature is what was found to lack in the literature and it is the main strength of this study.

\section{METHODOLOGY}

\subsection{Basics of LCA}

The environmental dimension of several decision processes has gained importance with the increasing environmental awareness. At the same time as a result of the technology and improvements of life standards, natural resources and global environmental issues are more often taken into account. Life Cycle Analysis (LCA) has become a more and more frequently used and continuously developed method in the complex decision making processes since the beginning of the 1990s [14]. LCA involves manufacturing of a product, transportation, consumption and also post-consumption waste treatment (if applicable). LCA is a method used to determine the environmental impacts associated with each of these stages, as well as to report and to manage them. LCA evaluates the all life cycle processes of a product or service and their connections with each other as a whole. Consequently, all kinds of environmental impacts of the assessed service or product from cradle to grave in all processes are revealed clearly [15]. A typical LCA analysis consists of four main steps $[16,17]$ :

i) Goal and Scope Definition: The goal \& scope definition is the most important step of LCA. The purpose of the study, scope, assumptions and limitations must be clearly defined in part.

ii) Inventory Analysis: Inventory analysis is necessary to identify data. At the inventory analysis step, consumption-production rates of the assessed product or service and the environmental emissions and consequent results based on these rates are determined.

iii) Impact Assessment: Impact assessment is the part where the impacts on human health, ecosystem quality and resources are identified according to the results of inventory analysis. Classification, weighting, normalization and characterization are the sub-steps for impact assessment. 
iv) Interpretation: In the interpretation step, the causal relationships are established for the obtained results, and appropriate solutions are investigated.

The interactions between these four steps can be better understood by looking at Figure 1 below.

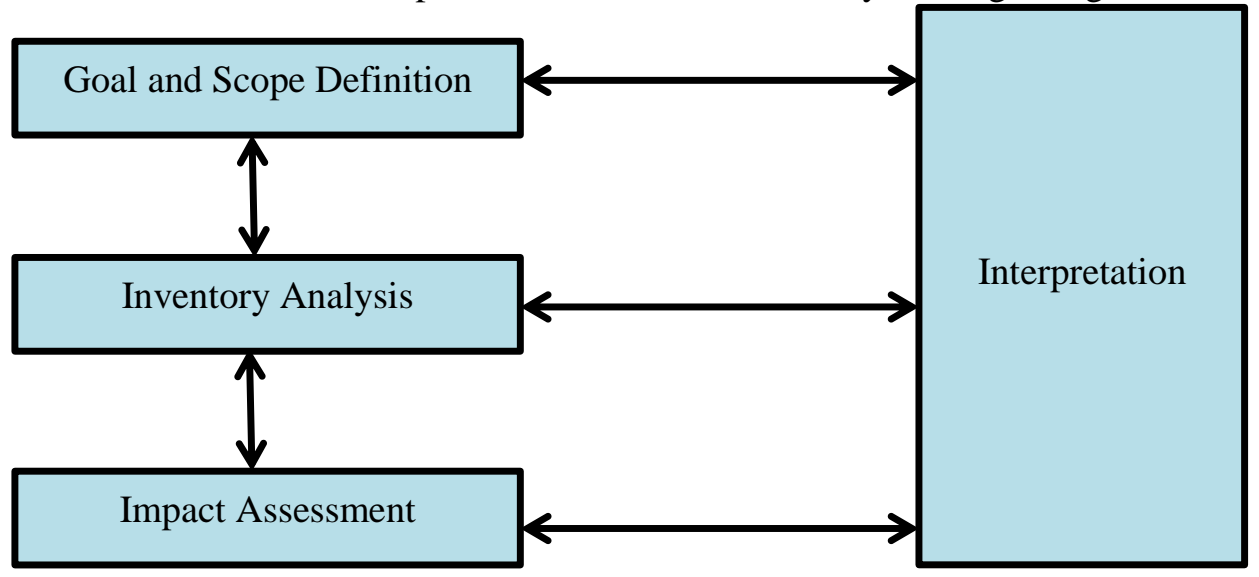

Figure 1. Steps of LCA Methodology

In this particular study, life cycle environmental impacts of electricity generation in Turkey and 3 other selected European countries were compared. The functional unit, i.e. the amount of electrical energy generated that corresponds to the reported environmental impacts, was chosen as $1 \mathrm{MWh}$ of electricity generated throughout the average useful lifetime of the energy generation plants, which was taken as 40 years. A cradle-to-grave approach was employed. The determination criteria for the countries to be compared to Turkey can be found in section 3.2. The specific LCA methodology which was used in this particular study is explained in section 3.3. Information regarding the acquisition of data is also present in section 3.3.

\subsection{Determination of the Countries to Compare and Their Electricity Mixes}

Turkey has a rather balanced electricity mix. The biggest share in the annual generation mix for year 2015 belongs to natural gas, with a percentage of 37.9. It is followed by coal and hydroelectricity, with percentages of 28.7 and 25.7, respectively. The entire electricity mix of Turkey can be seen in Figure 2 below:

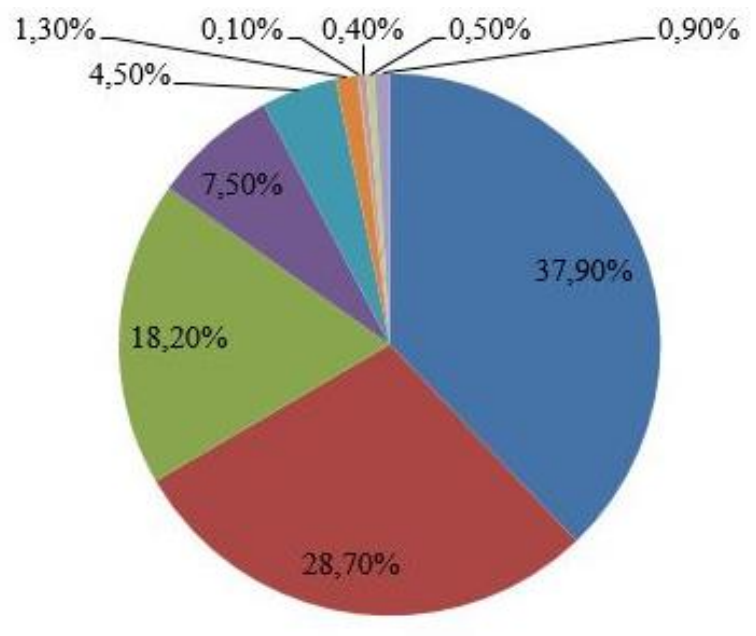

$\square$ Natural Gas
- Coal
$\square$ Hydroelectricity (reservoir)
$\square$ Hydroelectricity (run-of-the-mill)
$\square$ Wind
$\square$ Geothermal
$\square$ Solar
$\square$ Fuel Oil
$\square$ Diesel
$\square$ Others

Figure 2. Electricity mix of Turkey in 2015, percentages [18] 
It is estimated that the electricity mix of Turkey is not likely to lose its diverse characteristic in the near future. Despite the prospective addition of nuclear energy into the portfolio in 2019 (a second plant is scheduled for 2023 and national news agencies report that a third plant is planned to be built, however detailed information about the third plant was not available at the time of writing), Turkey will still probably continue to rely on fossil fuels, and especially coal, for electricity supply. At the same time Turkey is part of the Paris 2015 agreement and therefore she will have to gradually reduce her hazardous emissions, thus it is estimated that natural gas shall be continued to be imported for electricity generation [19].

The aim of this study was to compare the environmental impacts of electricity generation in Turkey with selected European countries in which electricity generation is dominated by one (but not the same) energy source. With this approach, it was aimed to observe where Turkish electricity sector, with its diverse structure, stands in relation to other countries' electricity sectors where the electricity mix is not as diverse as Turkey, from an environmental point of view. For that reason, the following three countries were selected for comparison:

i) Poland, where approximately $84 \%$ of the annual electricity generation comes from coal [20].

ii) France, where approximately $74 \%$ of the annual electricity generation comes from nuclear energy [20]

iii) Denmark, where approximately $53.3 \%$ of the annual electricity generation comes from renewables (almost entirely wind) [21].

In figures 3 to 5 below, the electricity mixes of Poland, France, and Denmark are presented.

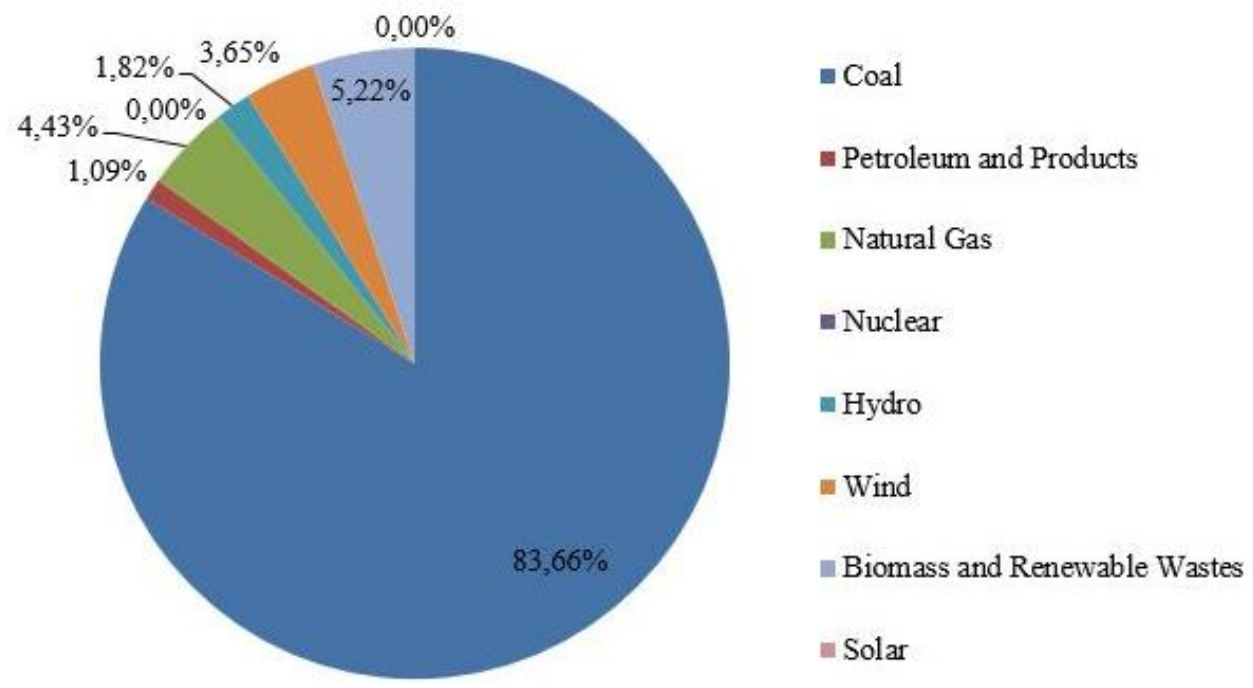

Figure 3. Electricity mix of Poland in 2015, percentages [20] 
Üçtuğ / Anadolu Univ. J. of Sci. and Technology A-Appl. Sci. and Eng. 18 (1)-2017

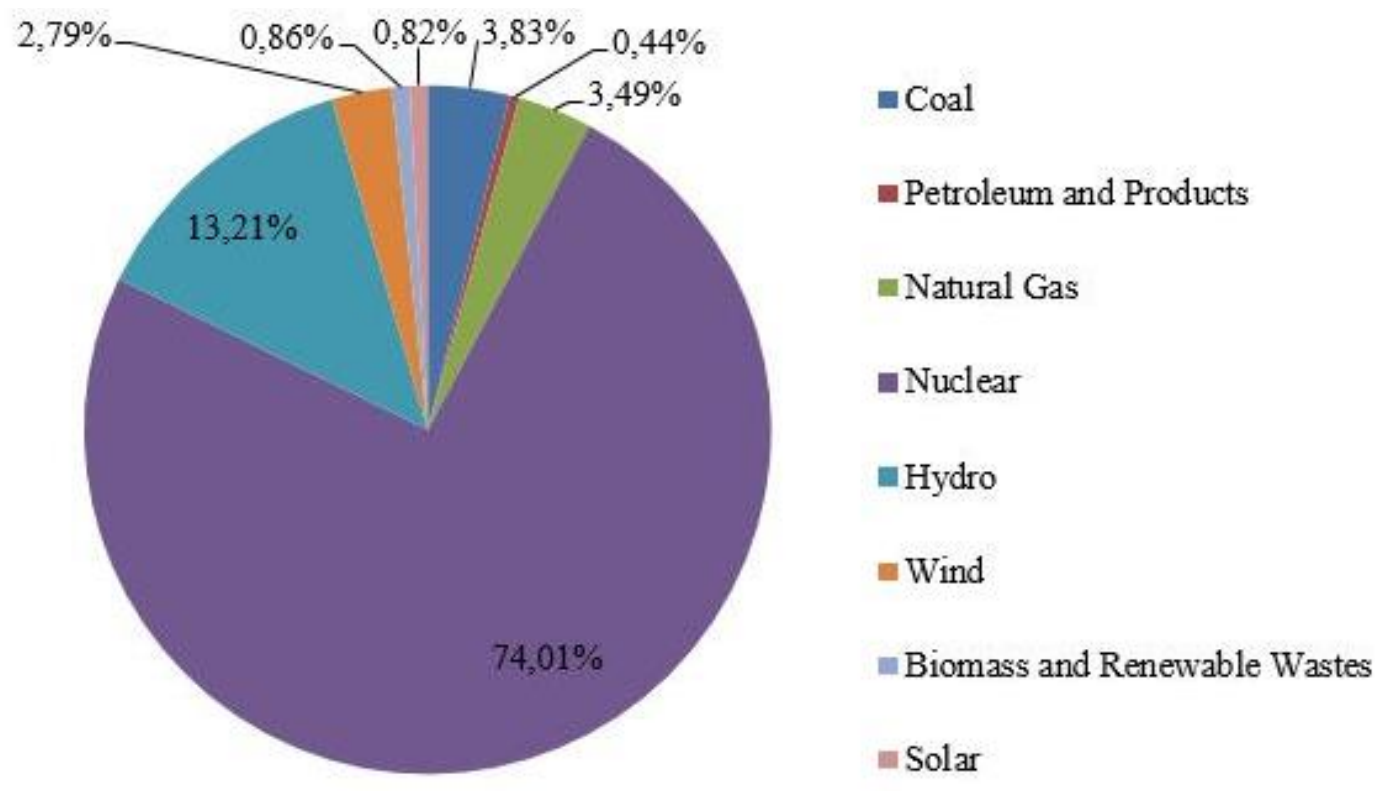

Figure 4. Electricity mix of France in 2015, percentages [20]

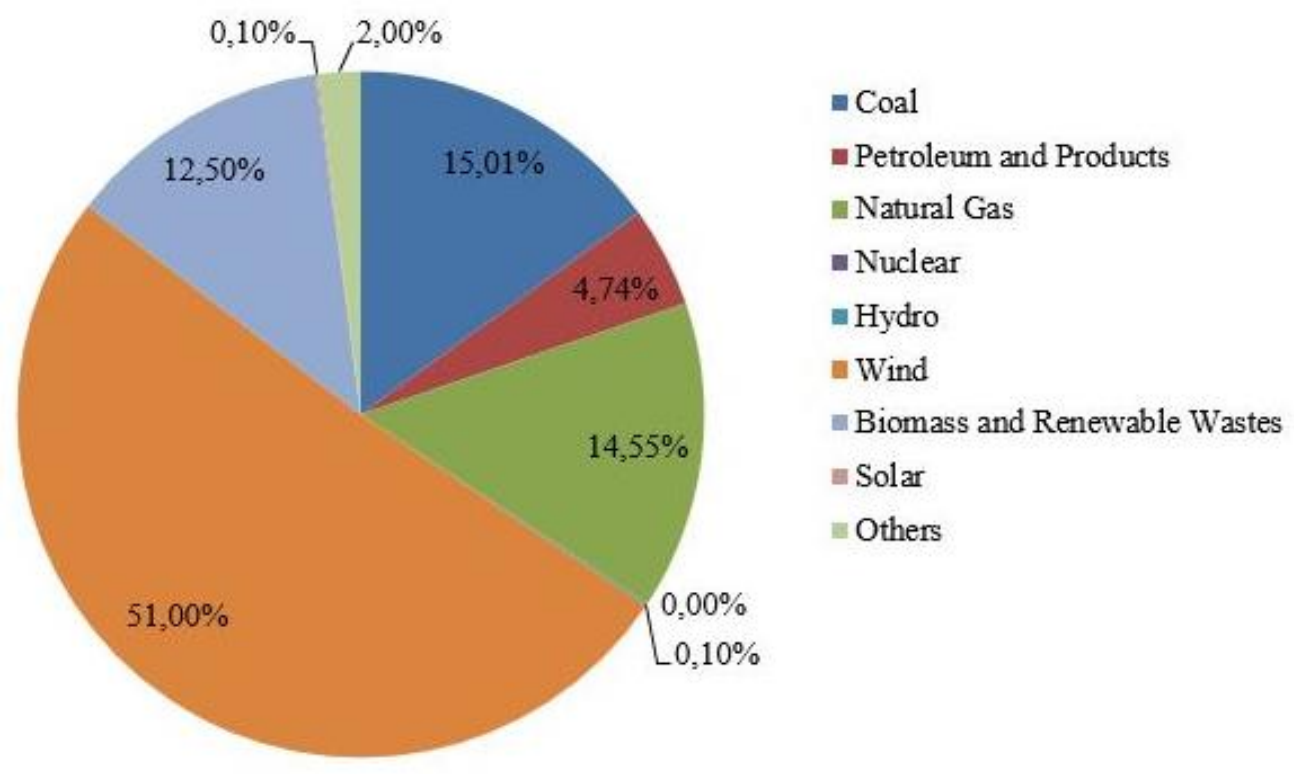

Figure 5. Electricity mix of Denmark in 2015, percentages [21] 


\subsection{LCA Methodology}

The electricity generation LCA results for Poland, France, and Denmark (220 V) were obtained by the author, by using OpenLCA v.1.5 software, ELCD v.3.2 database. Due to a lack of data for the Turkish case, the data published by Atilgan and Azapagic [13] were used. The system boundaries include the construction, operation, and the de-commissioning of the energy generating systems. For fossil fuel based systems, impacts associated with the acquiring the fuels were included only for the cases where the resources are obtained locally (such as lignite in Turkey).

CML2001, which is based on midpoint modeling, was chosen as the LCA methodology. "Midpoints are considered to be a point in the cause-effect chain (environmental mechanism) of a particular impact category, prior to the endpoint, at which characterization factors can be calculated to reflect the relative importance of an emission or extraction in a Life Cycle Inventory (e.g., global warming potentials defined in terms of radiative forcing and atmospheric half-life differences)" [22]. On the other hand, endpoint methodologies aim at assessing human health and ecosystem impacts as a result of a process that may occur as a result of climate change, ozone depletion, as well as other categories traditionally addressed using midpoint category indicators [22]. Figure 6 below clearly shows the distinction between midpoint and endpoint impact categories:

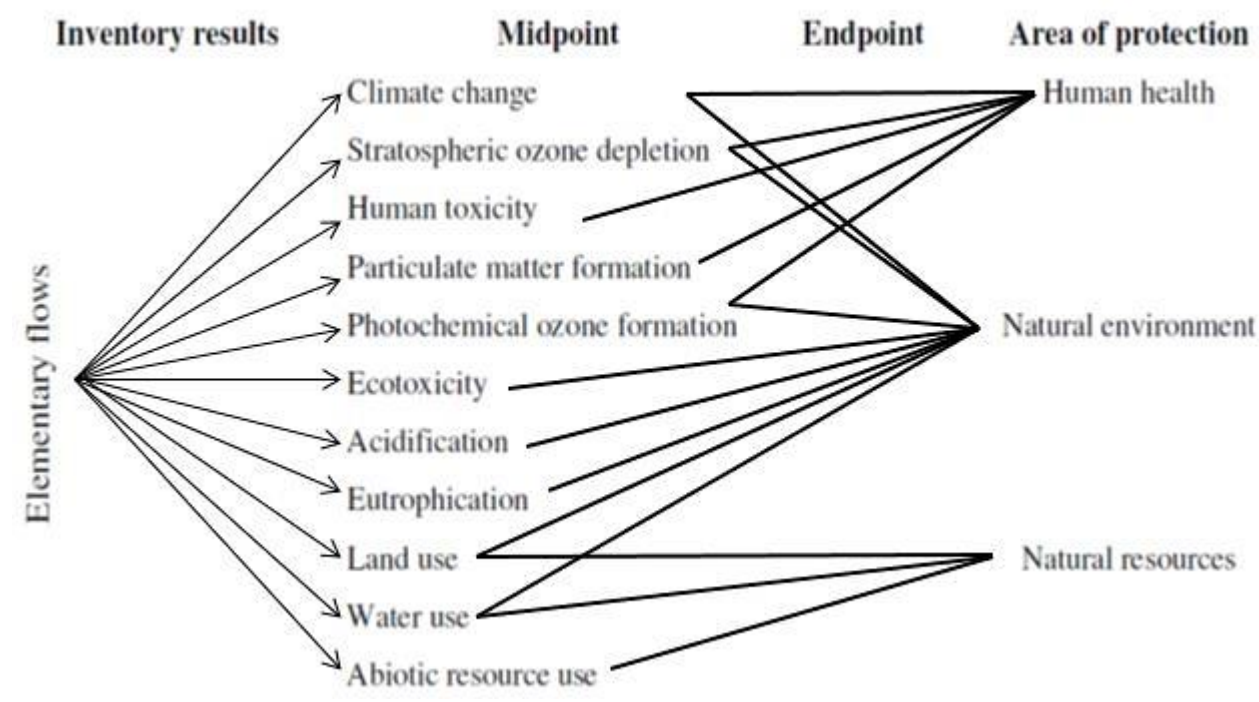

Figure 6. Midpoint and Endpoint impact categories [23]

The midpoint impact indicators considered in this study, and their brief descriptions, are as follows (in alphabetical order):

i) Acidification Potential $\left(\mathrm{kg} \mathrm{SO}_{2}\right.$ eq.)

Atmospheric deposition of inorganic substances on the Earth's surface, such as oxides of sulfur and nitrogen, are the basis of acidification in terrestrial and freshwater ecosystems, and to a lesser extent in (coastal) marine ecosystems. Their dissociation products alter alkalinity, $\mathrm{pH}$, and inorganic carbon storage in oceans. While these acidifying compounds have natural sources in volcanic eruptions and emissions from the oceans (e.g. volatile sulfur gases), most derive from anthropogenic activities, such as the combustion of fossil fuels at power stations and industrial plants, vehicle exhausts, and agriculture [23]. 
ii) Climate Change (Global Warming Potential) $\left(\mathrm{kg} \mathrm{CO}_{2}\right.$ eq.)

The climate change impact category refers to the warming of the climate system due to human activities, which is also called anthropogenic global warming. The emission of greenhouse gases (GHG) to the atmosphere is the leading cause of global warming. However, other climate forcing agents such as changes in terrestrial albedo and soot or aerosol emissions also have an impact on climate [23].

iii) Depletion of abiotic sources - elements (kg Sb eq.)

This impact category considers the use of all non-living resources, excluding energy sources. The most common example is the use of metals including uranium which is the energy source for nuclear processes [24].

iv) Depletion of abiotic sources - fossil fuels (MJ)

This impact category considers the use of all non-living and unprocessed resources that can be used directly to obtain energy. Examples are crude oil, natural gas reservoirs [24, 25]. The unit MJ refers to the extra effort that burdens the next generations for the use of resources today.

v) Eutrophication ( $\mathrm{kg} \mathrm{PO}_{4}^{-3}$ eq.)

Eutrophication is when the environment becomes enriched with nutrients and is an impact which is relevant mostly to agricultural activities. Anthropogenic increases in nitrogen and phosphorus inputs to terrestrial and aquatic ecosystems have driven increases in eutrophication, the occurrence of ecosystem changes due to over-supply of nutrients. Eutrophic water bodies exhibit changes in species composition that often include algal blooms and oxygen depletion, with occasionally arresting images of fish kills or dead zones [23].

vi) Freshwater aquatic ecotoxicity (kg 1,4-dichlorobenzene eq.)

This category indicator refers to the impact on fresh water ecosystems, as a result of emissions of toxic substances to air, water and soil. Ecotoxicity Potential (FAETP) is calculated by describing fate, exposure and effects of toxic substances. The time horizon is infinite. Characterization factors are expressed as 1,4-dichlorobenzene equivalents $/ \mathrm{kg}$ emission. The indicator applies at global/continental/ regional and local scale [26].

vii) Human Toxicity (kg 1,4-dichlorobenzene eq.)

This category concerns effects of toxic substances on the human environment. Health risks of exposure in the working environment are not included. Characterization factors, Human Toxicity Potentials (HTP), are calculated by describing fate, exposure and effects of toxic substances for an infinite time horizon. For each toxic substance HTP's are expressed as 1.4-dichlorobenzene equivalents/ $\mathrm{kg}$ emission. The geographic scope of this indicator determines on the fate of a substance and can vary between local and global scale [26].

viii) Marine aquatic ecotoxicity ( $\mathrm{kg}$ 1,4-dichlorobenzene eq.)

Method and approach-wise, marine aquatic ecotoxicity is calculated the same way as freshwater aquatic ecotoxicity, the only difference is that the affected ecosystem is not freshwater but marine (sea) water. In addition to process waste streams flowing directly (or after insufficient treatment) into the sea, the use of seawater for cooling of reactors and the consequent diffusion of hazardous chemicals into the water stream is also a major cause of marine aquatic ecotoxicity.

ix) Ozone layer depletion ( $\mathrm{NO}_{\mathrm{x}}$ ( $\mathrm{kg} \mathrm{CFC}-11$ eq.)

The stratospheric ozone layer plays a critical role in regulating conditions on Earth, but has been substantially depleted by CFC (chlorofluorocarbon) and other halocarbon emissions. This has increased the transmission of hazardous ultraviolet radiation to the Earth's surface, and been implicated in a range of negative human and ecosystem health impacts [23]. 
x) Photochemical oxidation (kg ethylene eq.)

Photochemical oxidants arise as the product of reactions between $\mathrm{OH}$-radicals, photochemical oxidants and the air pollutants nitrogen oxides (NOx) and non-methane volatile organic compounds (NMVOC) in the atmosphere. The photochemical oxidants are mainly ozone $\left(\mathrm{O}_{3}\right)$, peroxyacetyl nitrate and hydrogen peroxide. The main impact from photochemical oxidants on the natural environment is caused by an elevated $\mathrm{O}_{3}$ concentration. Excessive concentrations of tropospheric $\mathrm{O}_{3}$ have toxic effects on both plants and humans [23]. Photochemical oxidation is a major problem in urban areas where low quality fuels are used for central heating. Metropolitans such as Tahran or Beijing have been suffering from this impact for decades.

xi) Terrestrial ecotoxicity (kg 1,4-dichlorobenzene eq)

The calculation method, and also the unit, for this particular impact are also same as those for marine and freshwater aquatic ecotoxicity impacts. This category refers to impacts of toxic substances on terrestrial ecosystems.

\subsection{Deterination of the Weights}

In order to obtain the stakeholder opinion, a questionnaire was prepared in which the participants were asked to rank the 11 environmental indicators used in this study in the order of importance, with the most important one receiving a ranking of 11 and the least important one receiving a ranking of 1 . Once all the questionnaires were collected, the cumulative rankings for every single impact were calculated. Afterwards, these cumulative values were added and the entire sum was divided by each cumulative ranking score to calculate the weight value for that particular ranking. The mathematical expression of the methodology used to calculate the weights can be found below:

After all the results were collected, the scores for each criterion were summed up, as formulated below:

$$
T S_{z}=\sum_{k=1}^{n} P R_{z, k}
$$

In equation (1), TS stands for the total score of an individual criterion, $\mathrm{z}$ is the criterion index, $\mathrm{PR}$ is the individual rankings given by participants to criterion $\mathrm{z}, \mathrm{k}$ is the participant index, and finally $\mathrm{n}$ is the number of participants. Afterwards, the weights for each criterion were determined as follows:

$$
W_{z}=\frac{T S_{z}}{\sum_{z=1}^{11} T S_{z}}
$$

The questionnaire was sent by email to several experts in Turkey as well as the international community (academics, government officials, and private sector representatives involved in the field of either environmental impact analysis or life cycle analysis of energy systems). Out of the 163 people to whom this email was sent, 98 responded and 92 of them agreed to participate in the study. Out of these 92 people, 71 were academics, 17 were private sector representatives, and the remaining 5 were government officials. In addition to the ranking, the participants were also asked to quantify their experience by writing down the years for which they have been working in the field (excluding the prior studying). The average experience of the 92 participants was found to be 22.5 years.

\section{RESULTS AND DISCUSSION}

\subsection{Comparision of Individual Environmental Impacts}

In this section, all of the above-mentioned environmental impacts will be compared for the 4 countries and the results will be discussed in reference to the electricity mixes of the countries. 


\subsubsection{Acidification potential (AP)}

As depicted on Figure 7, Turkey and Poland have much higher acidification potential scores than Denmark or France. This is not surprising as fossil fuels have a high share in the electricity mixes of both Poland and Turkey. Lignite coal is known to be approximately twice more hazardous in terms of acidification potential when compared to hard coal [13], and this can explain why Turkey has a higher acidification potential than Poland. This finding is especially interesting when we consider that the share of coal in Poland's electricity mix is approximately $84 \%$ while for Turkey this value is around 29\%. However, the quality of coal utilized in Poland is higher than Turkey [27], and Turkish coal (lignite) has very high sulfur content and many power plants in Turkey operate without desulfurization units.

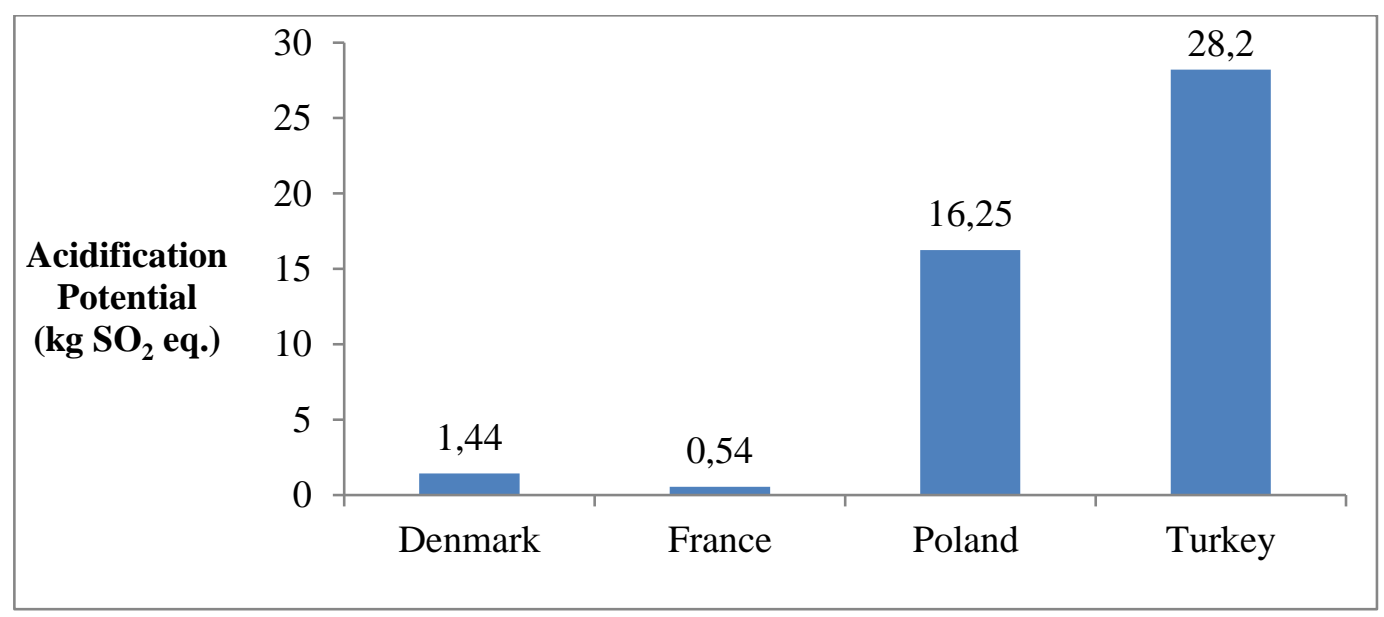

Figure 7. Comparison of electricity generation in Denmark, France, Poland, and Turkey in terms of acidification potential

\subsubsection{Global warming potential}

Figure 8 shows that the GWP scores of Poland and Denmark are higher than that of Turkey, with France having the lowest score. The fact that Poland has the highest GWP score is not surprising, as hard coal has much higher carbon content than lignite and therefore the combustion of hard coal leads to significant $\mathrm{CO}_{2}$ emissions, thereby increasing the GWP score. What is interesting about the data presented in Figure 8 is that Denmark, despite generating almost $50 \%$ of its electricity from wind, has a higher GWP score than Turkey. It has been shown in the literature that Germany, another country in which the share of renewables in the overall electricity mix is also high, has a higher GWP score than Turkey as well [28]. The relatively high GWP score of Denmark can be attributed to the abundance of off-shore wind power plants, whose construction requires steel and cement, and the production of these materials are highly energy-intensive [29]. 


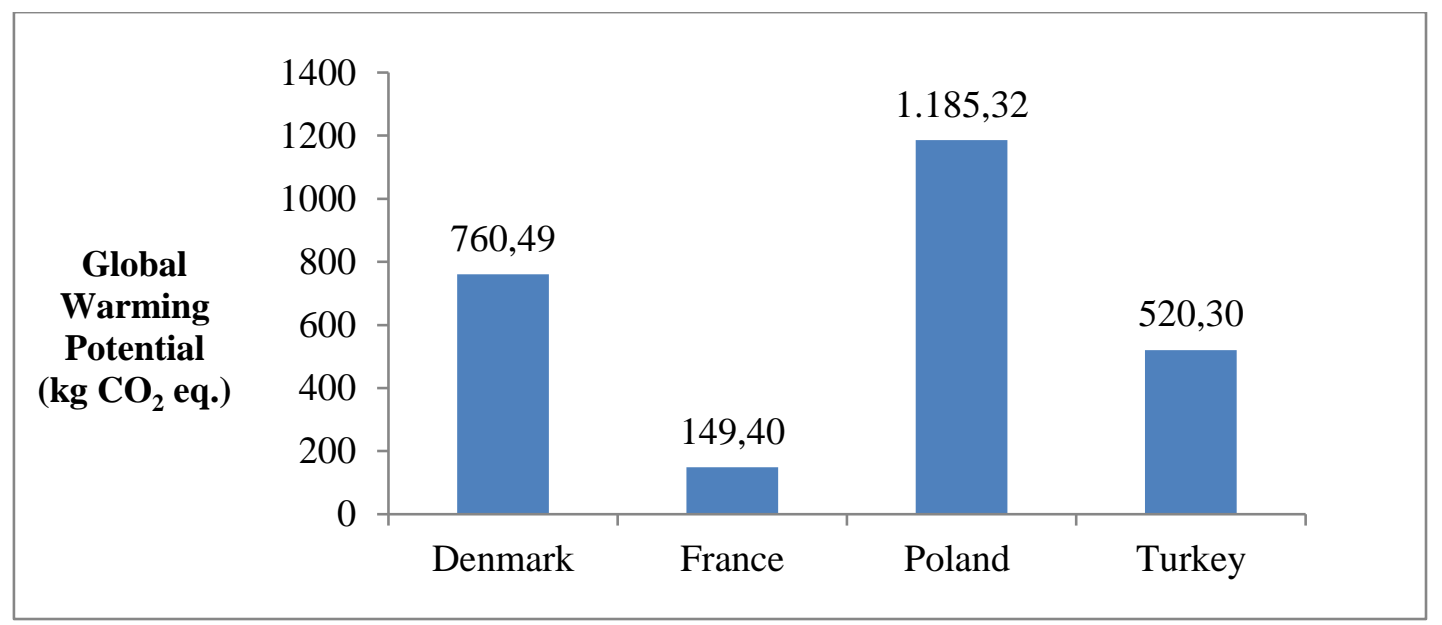

Figure 8. Comparison of electricity generation in Denmark, France, Poland, and Turkey in terms of global warming potential

\subsubsection{Depletion of abiotic sources - elements (DASe)}

It has been reported in the literature that renewable systems such as wind or solar require high levels of metal input for construction [7]. The same is also valid for nuclear systems; furthermore nuclear systems also require uranium to generate electricity. Despite being the energy source in that case, the depletion of uranium is considered under the DASe category rather than the DASf category, as explained before. For these reasons, France and Denmark turned out to have much higher scores in this category when compared to Poland or Turkey.

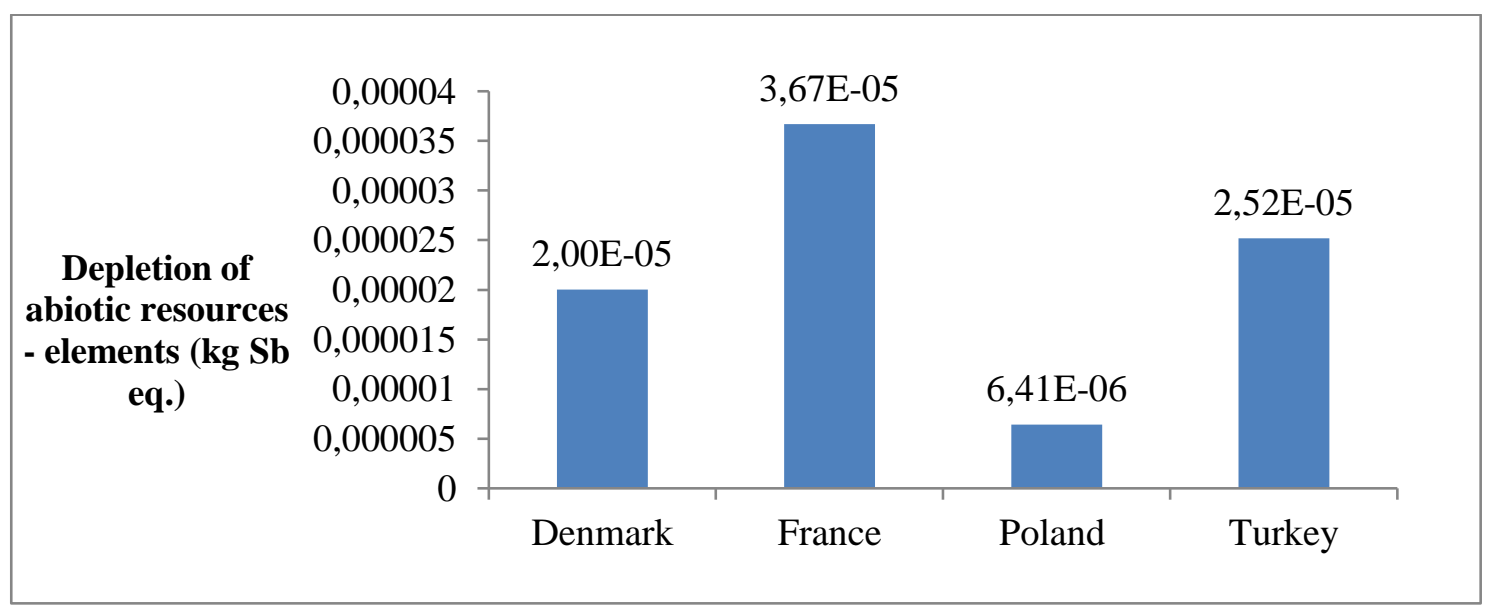

Figure 9. Comparison of electricity generation in Denmark, France, Poland, and Turkey in terms of depletion of abiotic sources - elements

\subsubsection{Depletion of abiotic sources - fossil fuels (DASf)}

It is obvious that DASf score is directly relevant to the use of natural gas, coal, or oil. Therefore it is not surprising that Poland and Turkey, in which fossil fuels contribute to $90 \%$ and $70 \%$ of the overall electricity generation, respectively, have higher DASf scores than France or Denmark. The fact that France has a much lower score than Denmark can be explained as follows: Wind and nuclear energy systems are both highly energy-intensive to construct, however nuclear energy systems usually have 
longer lifespans, much higher annual energy output (due to both high power ratings and high capacity factor of nuclear energy) when compared to wind energy systems. Therefore when it comes to calculating the DASf score on a life cycle basis per kWh of electricity, France turns out to have a much lower score than Denmark.

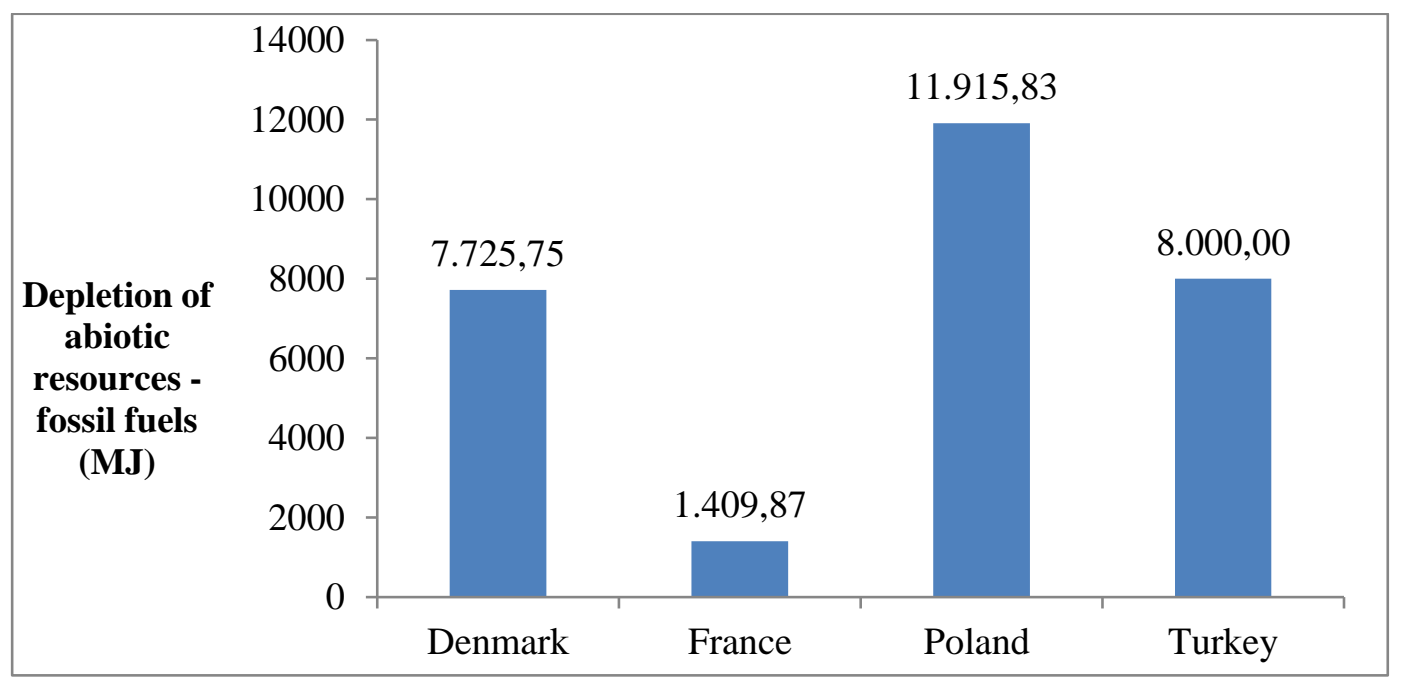

Figure 10. Comparison of electricity generation in Denmark, France, Poland, and Turkey in terms of depletion of abiotic sources - fossil fuels

\subsubsection{Eutrophication (EUT)}

Eutrophication and acidification have very similar mechanisms, and indeed in some LCA methods such as Eco-indicator, they are combined into a single impact. Therefore the data presented in Figure 11 is not contrary to the expectations. Poland and Turkey, in which coal has a significant share in the overall electricity mix, have much higher EUT scores than France or Denmark. This trend can be attributed to the $\mathrm{NO}_{\mathrm{X}}$ emissions due to coal combustion [30].

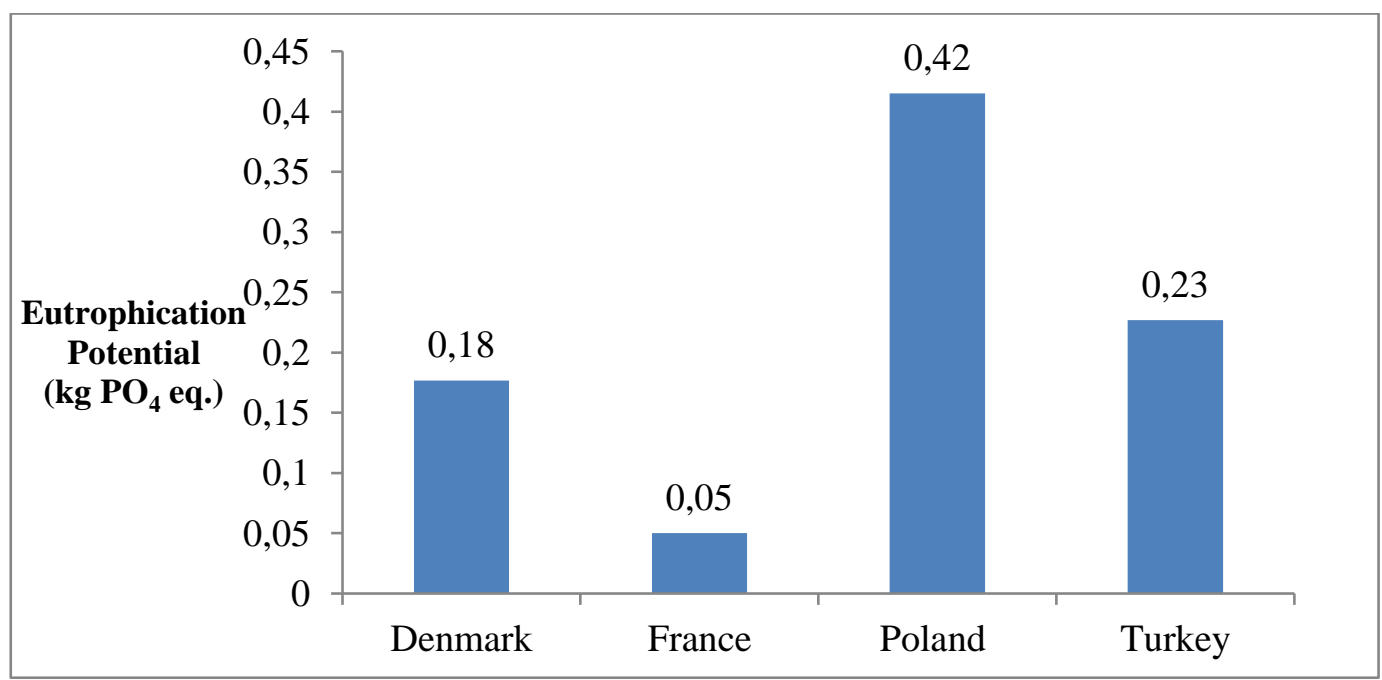

Figure 11. Comparison of electricity generation in Denmark, France, Poland, and Turkey in terms of eutrophication 


\subsubsection{Freshwater aquatic ecotoxicity (FAET)}

As can be seen in Figure 12, Turkey has much higher FAET score than the rest of the group. This can be explained as follows: Lignite is known to be the energy source with the highest FAET score, mainly due to the emissions of metals such as nickel, beryllium, cobalt, vanadium, copper, and barium into freshwater streams during mining processes. Hard coal used in Poland has approximately $20 \%$ of the FAET score of lignite. Renewables are usually one order of magnitude less hazardous when it comes to freshwater ecotoxicity [13]. At the first glance, the higher score of France with respect to Poland seemed interesting. In order to get further insight on the issue, the life cycle inventory data (outputs to fresh water) for the two countries was carefully investigated. It was observed that for the following metals, the effluents into fresh water in the case of France were at least 3 orders of magnitude higher: Antimony, Beryllium, Cesium, Cobalt, Manganese, Plutonium, Radium, Ruthenium, Silver, Strontium, Titanium, and Uranium. Amongst these, 6 are reported to be highly relevant to FAET indicator (Beryllium, Cesium, Cobalt, Manganese, Copper, and Strontium) [31]. Most of these chemicals are thought to mix into the underground or open-air freshwater streams as a result of Uranium mining.

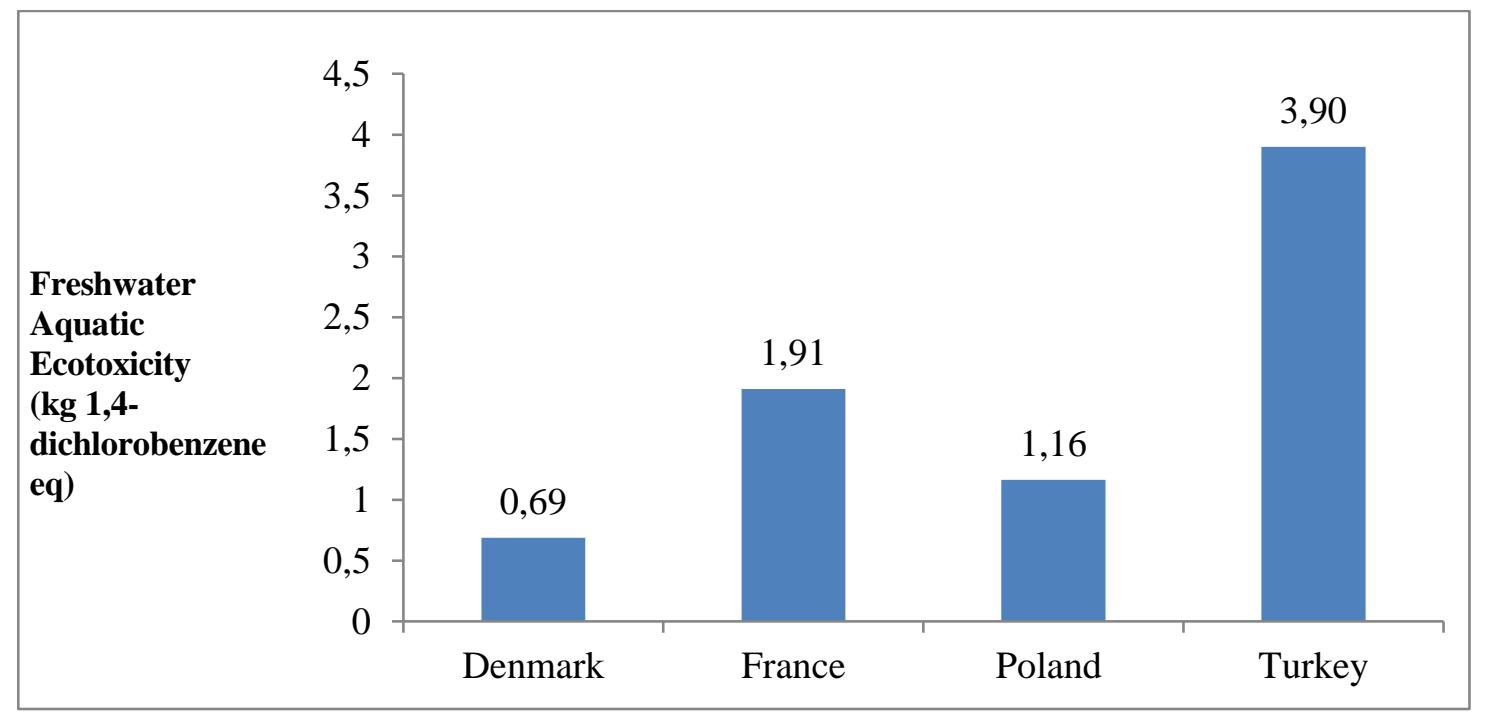

Figure 12. Comparison of electricity generation in Denmark, France, Poland, and Turkey in terms of freshwater aquatic ecotoxicity

\subsubsection{Human toxicity (HT)}

Coal mining and coal combustion are the two most hazardous processes according to the literature [13], and this fact is clearly evident when the results shown in Figure 13 are investigated. Despite having a lower share of coal in the electricity mix, Turkey's HT score is higher than that of Poland, mostly due to the low quality of lignite used in Turkey when compared to the hard coal used in Poland. As far as Denmark and France are concerned, the explanation made in section 4.1.7 is also valid in this case. The high-energy intensity of wind energy systems (especially offshore), coupled with the relatively low capacity factor of wind energy, leads to a higher HT score in the case of Denmark. 
Üçtuğ / Anadolu Univ. J. of Sci. and Technology A-Appl. Sci. and Eng. 18 (1)-2017

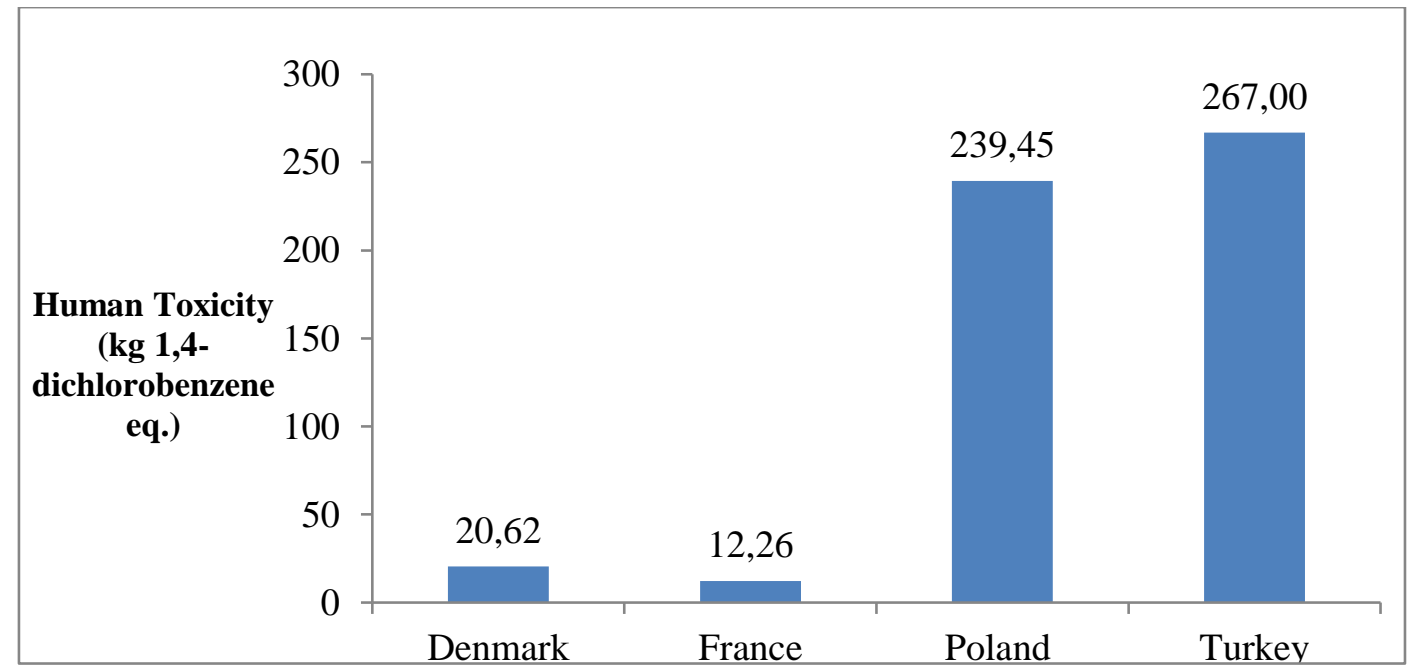

Figure 13. Comparison of electricity generation in Denmark, France, Poland, and Turkey in terms of human toxicity

\subsubsection{Marine aquatic ecotoxicity (MAET)}

MAET scores are also known to be increased as a result of coal mining activities, and that is why the data presented in Figure 14 shows that Poland and Turkey have very high HT scores than Denmark or France. Hydrogen fluoride (HF) output is the biggest contributor to MAET score [6], and Poland's HF score is one order of magnitude higher than Denmark and two orders of magnitude higher than France, according to the life cycle inventory data.

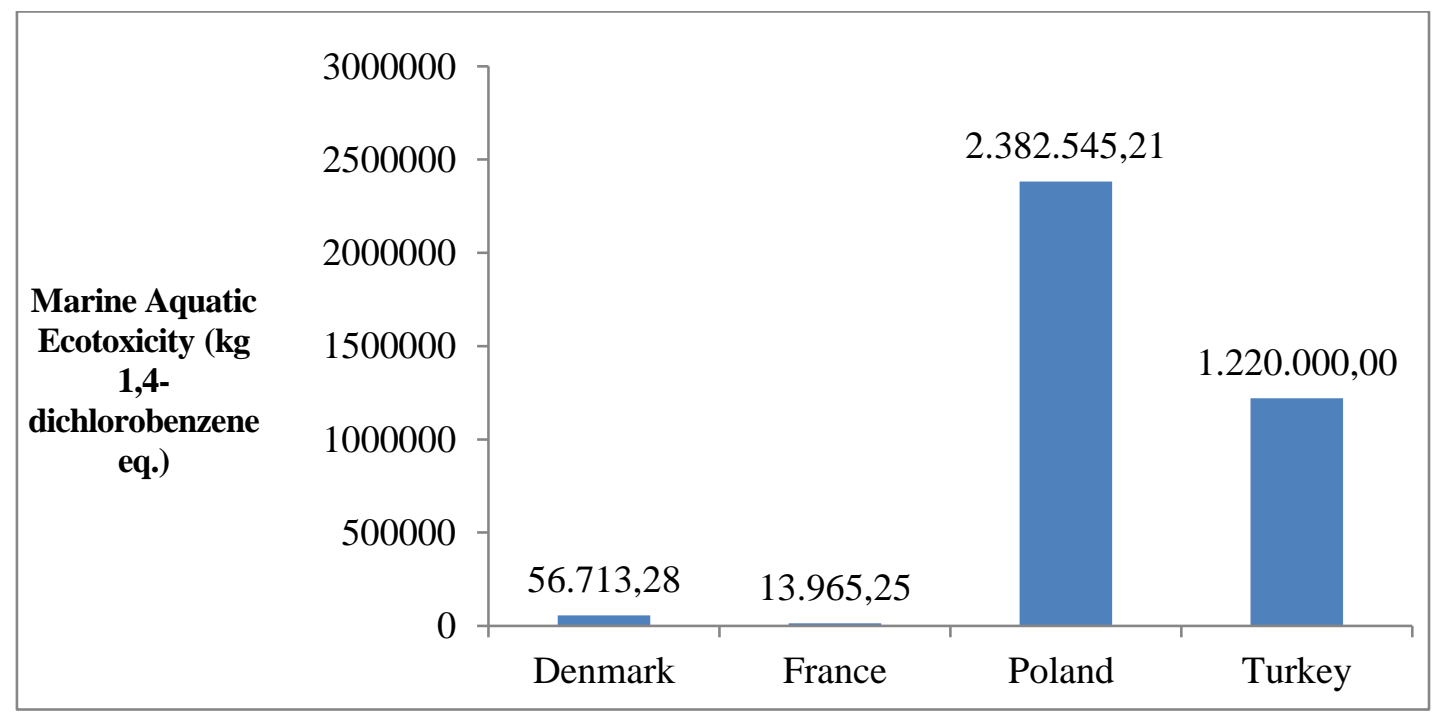

Figure 14. Comparison of electricity generation in Denmark, France, Poland, and Turkey in terms of marine aquatic ecotoxicity

\subsubsection{Ozone layer depletion (OLD)}

One of the most interesting results of this study is displayed in Figure 15. Nuclear energy is known to be one of the most environmentally friendly energy sources, but when it comes to OLD, the situation is just the opposite. The fact that France's OLD score is much higher than all the other three countries combined indicates that nuclear energy must have a high OLD score. And there is evidence of that in 
literature [20, 32]. Amongst many chemicals that cause the thinning of the ozone layer, one of the most problematic ones is CFC-114 (or Freon), an industrial coolant. One of the fields where CFC-114 is commonly used is the uranium enrichment plants, for the purpose of cooling. Hence countries like France where nuclear energy is the dominant electricity source, have high ozone layer depletion scores.

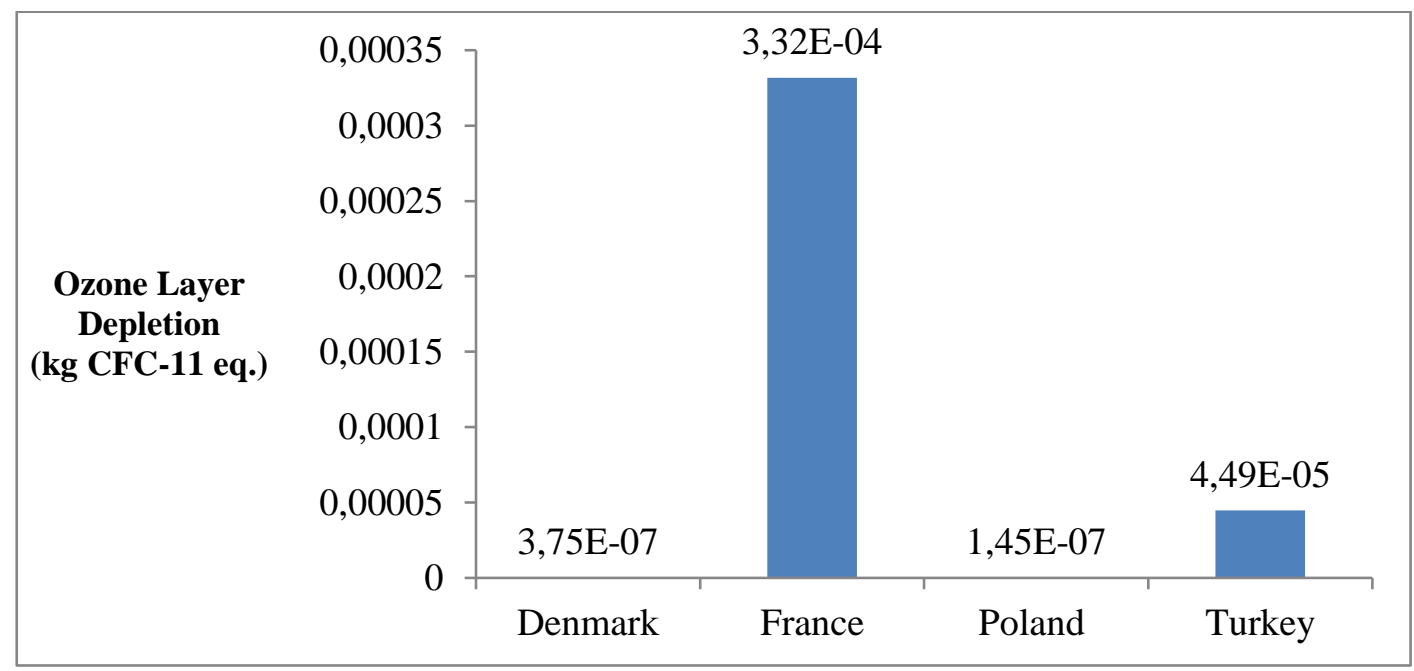

Figure 15. Comparison of electricity generation in Denmark, France, Poland, and Turkey in terms of ozone layer depletion

\subsubsection{Photochemical oxidation (PCO)}

PCO scores are mostly affected by the emission of $\mathrm{SO}_{2}, \mathrm{NO}_{\mathrm{x}}$ and $\mathrm{CO}$ into the atmosphere [1], all of which are products of coal combustion. Therefore Poland and Turkey have much higher scores of PCO when compared to Denmark or France.

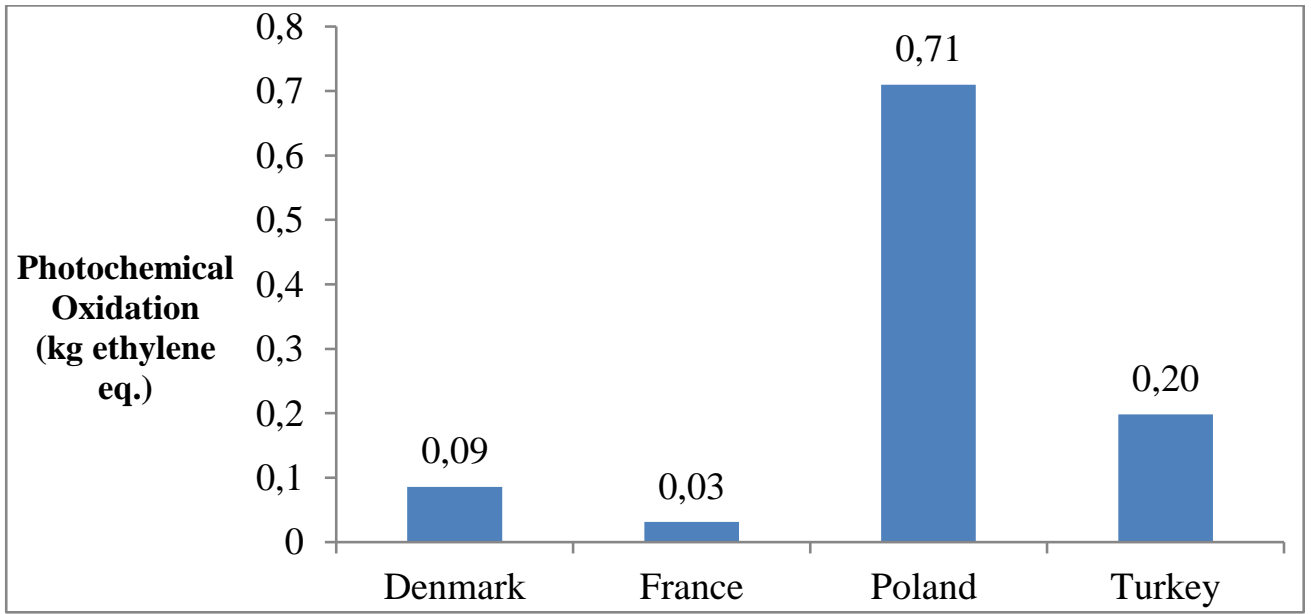

Figure 16. Comparison of electricity generation in Denmark, France, Poland, and Turkey in terms of photochemical oxidation 


\subsubsection{Terrestrial ecotoxicity (TET)}

Again, coal combustion is the biggest cause of TET; therefore Poland and Turkey have higher scores than the other two. It is stated in the literature that wind energy systems also have relatively high TET scores due to the excess amounts of metal required to construct the system, and mining of these metals lead to hazardous emissions and effluents $[1,13]$.

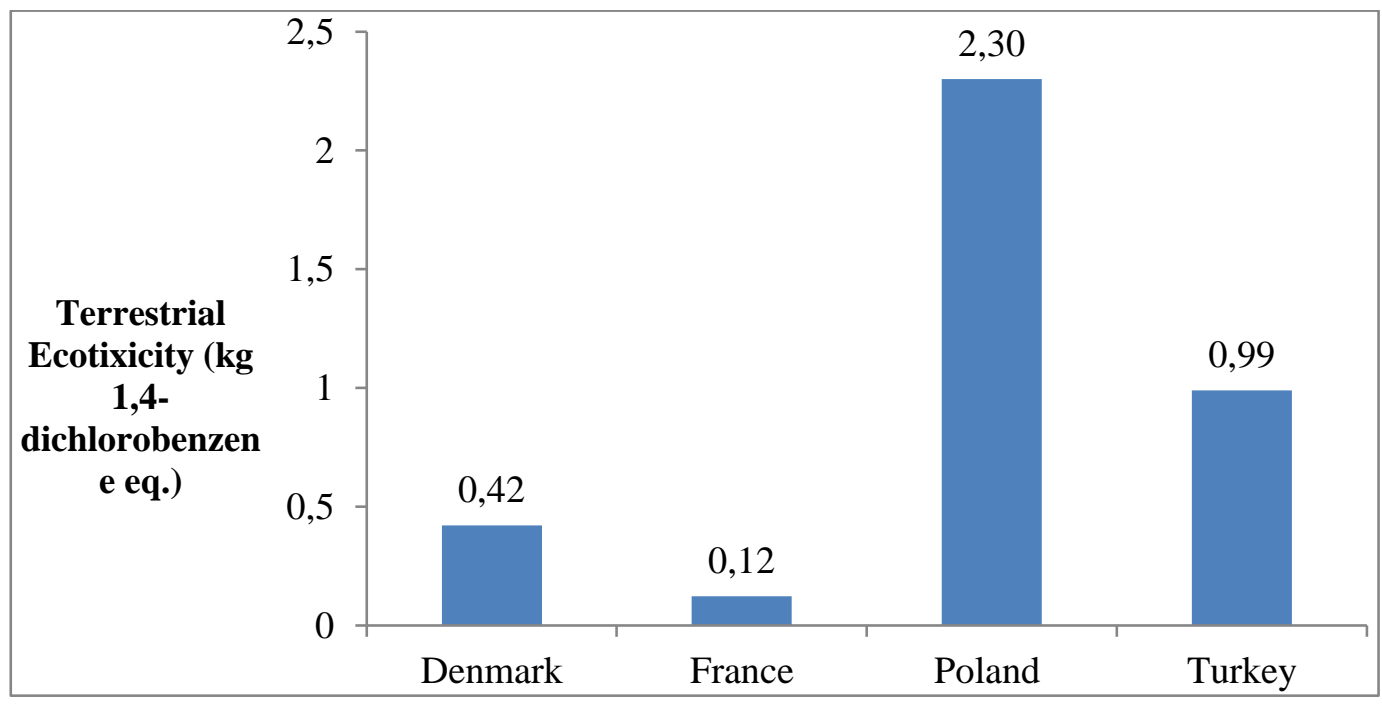

Figure 17. Comparison of electricity generation in Denmark, France, Poland, and Turkey in terms of terrestrial ecotoxicity

\subsection{Overall Environmental Comparison of Countries}

In order to be able to compare the overall environmental impacts, the first step is to normalize the scores. That is essential because different impacts have different units and orders of magnitude. Normalization was realized by finding the sum of each impact by adding up the individual impact values of all countries for that impact, and then dividing each country's impact score by that sum. The normalized impact score table can be found below.

Table 1. Normalized environmental impact scores

\begin{tabular}{l|c|c|c|c} 
& Denmark & France & Poland & Turkey \\
\hline AP & 0.031 & 0.012 & 0.350 & 0.607 \\
\hline GWP & 0.291 & 0.057 & 0.453 & 0.199 \\
\hline DASe & 0.227 & 0.415 & 0.073 & 0.285 \\
\hline DASf & 0.266 & 0.049 & 0.410 & 0.275 \\
\hline EUT & 0.203 & 0.058 & 0.478 & 0.261 \\
\hline FAET & 0.090 & 0.249 & 0.152 & 0.509 \\
\hline HT & 0.038 & 0.023 & 0.444 & 0.495 \\
\hline MAET & 0.015 & 0.004 & 0.649 & 0.332 \\
\hline OLD & 0.001 & 0.880 & 0.000 & 0.119 \\
\hline PCO & 0.084 & 0.031 & 0.692 & 0.193 \\
\hline TET & 0.110 & 0.032 & 0.600 & 0.258
\end{tabular}




\subsubsection{Case of uniform weight distribution}

According to Figure 18, electricity generation in Poland has the highest overall environmental impact whereas Denmark has the cleanest electricity mix amongst the four countries. These findings are in line with the expectations, as Poland relies mainly on coal while Denmark relies mainly on wind energy for electricity supply. Turkey, currently, stands closer to Poland in the scale. But with the addition of nuclear and solar energies into the mix as well as the development of low carbon coal technologies in the coming years, it is thought that Turkey's overall environmental impact score for electricity generation is likely to decrease.

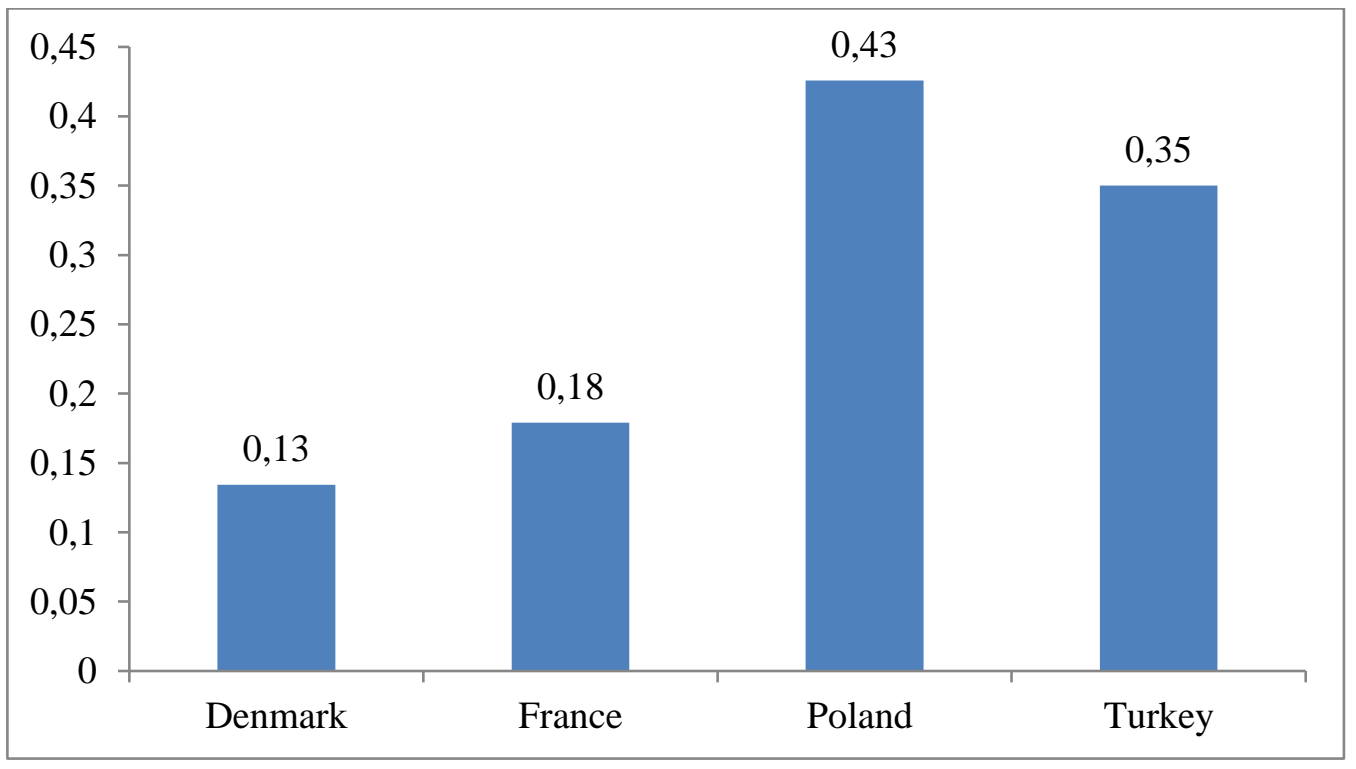

Figure 18. Overall environmental impact comparison of electricity generation in Denmark, France, Poland, and Turkey (equal weights)

\subsubsection{Case of weight distribution according to stakeholder opinion}

In Table 2 below, the weight distribution obtained according to the opinions of the stakeholders can be found. The calculation method of the weights was already explained in section 3.4.

Table 2. Weight values for the impacts based on stakeholder opinions

\begin{tabular}{lc}
\hline \multicolumn{1}{c}{ Environmental Impact Type } & Weight \\
\hline Acidification & $2.00 \%$ \\
Climate change & $23.00 \%$ \\
Depletion of abiotic resources - elements & $13.00 \%$ \\
Depletion of abiotic resources - fossil fuels & $19.00 \%$ \\
Eutrophication & $6.00 \%$ \\
Freshwater aquatic ecotoxicity & $6.00 \%$ \\
Human toxicity & $16.00 \%$ \\
Marine aquatic ecotoxicity & $3.00 \%$ \\
Ozone layer depletion & $7.00 \%$ \\
Photochemical oxidation & $2.00 \%$ \\
Terrestrial ecotoxicity & $3.00 \%$ \\
\hline
\end{tabular}

Table 2 shows that climate change is perceived as the greatest threat to the environment with a weight of $23 \%$, followed by depletion of abiotic resources-elements and human toxicity, whose weights were 
calculated as $19 \%$ and $16 \%$, respectively. Acidification potential and photochemical oxidation were seen as the least important environmental impacts, with both receiving a weight of $2 \%$.

The overall environmental impact calculation whose results are depicted below in Figure 19 was realized by multiplying the normalized scores for each impact in Table 1 by the corresponding weight for that impact in Table 2, and then adding the weighted impact values for each country.

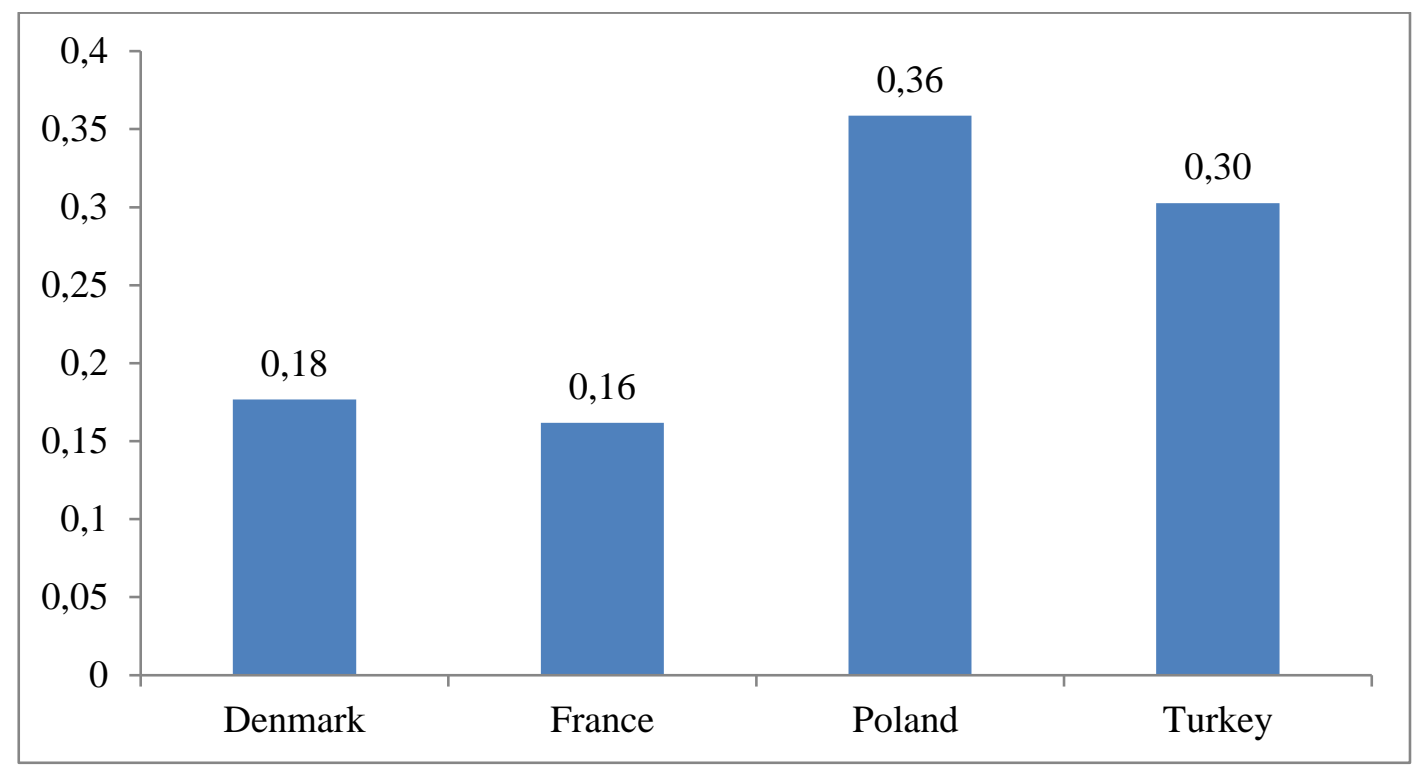

Figure 19. Overall environmental impact comparison of electricity generation in Denmark, France, Poland, and Turkey (weights based on stakeholder opinion)

According to the stakeholder opinion, Poland and Turkey still have higher environmental impacts than Denmark or France; however the gap between Poland and Turkey is narrowed. Furthermore, Denmark's overall environmental impact score is now slightly higher than that of France. This shows us that the energy source that satisfies the expert expectation in Turkey the most in terms of environmental impact is nuclear energy. These findings are also encouraging from the point of view of Turkey, where the introduction of cleaner energy technologies into the electricity mix is not only going to decrease the environmental impact of electricity generation, but also improve energy security.

\section{CONCLUSION}

The overall environmental impact of electricity generation in Turkey was compared to selected countries in Europe. The impact data for Turkey was taken from literature, whereas the impact data for the selected countries was calculated by using OpenLCA software and ELCD database. The countries to be compared to Turkey were selected as Denmark, France, and Poland. The idea behind this selection was to compare the diverse electricity mix of Turkey to specific countries in which the electricity mix is dominated by one energy source. In the case of Denmark, this source happens to be wind; for France it is nuclear; and finally for Poland it is coal. CML2001 method was employed for comparison. The functional unit was selected as $1 \mathrm{MWh}$ of electricity generated throughout the average useful lifetime of the plants, and the approach was cradle-to-grave. The main novelty of this paper is the use of stakeholder opinion in order to determine weights for different impacts so that overall impact scores can be calculated for each country.

One of the most striking findings of this study is that although the share of coal in Turkey's electricity mix is much less than that of Poland, the acidification score of Turkish energy is much higher than 
Poland. This can be attributed to the high sulfur content in Turkish coal. Other coal-related environmental impacts such as ecotoxicity or human toxicity are also high in case of Turkey. These trends point out to an alarming situation. It is a well-known fact that Turkey is heavily dependent on imports for primary and secondary energy supply, and the use of local resources such as lignite is very important as far as energy security and economic prosperity are concerned. However, environmental precautions shall be taken and legal framework that enforces such precautions must be carefully created so that the environmental impact of lignite utilization can be minimized.

Another interesting conclusion that can be reached is the fact that France, which is a country that relies mainly on nuclear energy for electricity supply, was found to have to lowest overall environmental impact score based on the opinion of the stakeholders. Turkey is in the process of adding nuclear energy into its national energy mix, however there has been an ongoing public debate on whether nuclear energy is safe and environmentally friendly or not. The results of this particular study is a clear indication that nuclear energy is an environmentally friendly method of electricity supply.

The energy sector in Turkey is awaiting significant changes such as the introduction of nuclear energy into the energy mix, increasing the share of solar energy in the mix and a consequent decrease in the share of natural gas. Furthermore, the Ministry of Energy recently announced that studies and investments on clean coal technologies shall be incentivized. All these developments help lead to the conclusion that the environmental impact of electricity generation in Turkey is likely to decrease in the future.

\section{REFERENCES}

[1] Santoyo-Castelazo E, Gujba H and Azapagic A. Life cycle assessment of electricity generation in Mexico, Energy, no. 36, pp. 1488-1499, 2011.

[2] Herbert AS, Azzaro-Pantela C and Le Boulch D. A typology for world electricity mix: Application for inventories in Consequential LCA (CLCA), Sust Prod Consump, vol. http://dx.doi.org/10.1016/j.spc.2016.09.002, no. Article in press, 2016.

[3] Hopwood D. The world waits for COP to deliver, Renew. Energy Focus, no. 16, pp. 5-6, 2015.

[4] Framework convention on climate change. Report of the Conference of the Parties on its twenty first session, held in Paris from 30 November to 11 December 2015, United Nations, Paris, 2016.

[5] Santoyo-Castelazo E and Azapagic A. Sustainability assessment of energy systems: integrating environmental, economic and social aspects, J Clean Prod, no. 80, pp. 119-138, 2014.

[6] Brizmohun R, Ramjeawon T and Azapagic A. Life cycle assessment of electricity generation in Mauritius, J Clean Prod, no. 106, pp. 565-575, 2015.

[7] Stamford L and Azapagic A. Life cycle sustainability assessment of UK electricity scenarios to 2070, Energy Sustain Dev, no. 23, pp. 194-211, 2014.

[8] May J and Brennan D. Sustainability assessment of Australian electricity generation, Process Saf Environ, no. 84, pp. 131-142, 2006.

[9] Kannan R, Leong K, Osman R and Ho H. Life cycle energy, emissions and cost inventory of power generation technologies in Singapore, Renew Sust Energ Rev, no. 11, pp. 702-715, 2007. 
[10] Gujba H, Mulugetta $\mathrm{Y}$ and Azapagic A. Environmental and economic appraisal of power generation capacity expansion plan in Nigeria, Energ Policy, no. 38, pp. 5636-5652, 2010.

[11] Atilgan B and Azapagic A. Life cycle environmental impacts of electricity from fossil fuels, J Clean Prod, no. 106, pp. 555-564, 2015.

[12] Atilgan B and Azapagic A. Renewable electricity in Turkey: Life cycle environmental impacts, Renew Energ, no. 89, pp. 649-657, 2016.

[13] Atilgan B and Azapagic A. An integrated life cycle sustainability assessment of electricity generation in Turkey, Energ Policy, no. 93, pp. 168-186, 2016.

[14] J. Guinee, Heijungs R, Huppes G, Zamagni A, Masoni, P, Buonamici R E T and Rydberg T. "Life Cycle Assessment: Past, Present, and Future," Environ Sci Technol, no. 45, pp. 90-96, 2011.

[15] Owens J. Life cycle assessment: Constraints on moving from inventory to impact assessment, J Ind Ecol, no. 1, pp. 37-49, 1997.

[16] International Standard ISO 14040: Environmental management-life cycle assessmentprinciples and framework, 2006.

[17] International Standard ISO 14044: Environmental management-life cycle assessmentrequirements and guidelines, 2006.

[18] Turkey Electrical Energy Statistics, Chamber of Electrical and Electronics Engineers (EMO), 18 8 2016. [Online]. Available: http://www.emo.org.tr/genel/bizden_detay.php?kod=88369\#.VpwsPnhCM8 (in Turkish). [Accessed 279 2016].

[19] Turkey's Energy Profile and Strategy, Turkish Ministry of Foreign Affairs, [Online]. Available: http://www.mfa.gov.tr/turkiye_nin-enerji-stratejisi.tr.mfa (in Turkish). [Accessed 269 2016].

[20] Üçtuğ G and Alevli G "Life Cycle Analyses of Electricity Generation in Ten Major European Countries," in 39th IAEE International Conference - Energy: Expectations and Uncertainty, Bergen, Norway, 2016.

[21] Electricity Generation in Denmark, Energinet.dk, [Online]. Available: http://www.energinet.dk/EN/KLIMA-OG-MILJOE/Miljoerapportering/Elproduktion-i-Danmark/Sider/ Elproduktion-i-Danmark.aspx. [Accessed 279 2016].

[22] Bare J, Hofstetter P, Haes PD and Udo de Haes H. Midpoints versus endpoints: The sacrifices and benefits, Int. J. Life Cycle Ass., vol. 5, pp. 319-326, 2000.

[23] Hauschild M and Huijbregts M. Life Cycle Impact Assessment, Dordrecht: Springer, 2015.

[24] Huppes G. Abiotic Resource Depletion in LCA, Holland Road and Hydraulic Engineering Institute, Amsterdam, 2002.

[25] van Oers L and Guinée J. The Abiotic Depletion Potential: Background, Updates, and Future, Resources, vol. 5, no. 16, pp. 1-12, 2016. 
[26] Garrett P and Collins M. Life cycle assessment of product stewardship options for mercurycontaining lamps in New Zealand: Final report, New Zealand Ministry for the Environment, New Zealand, 2009.

[27] Coal in Poland World Energy Council, [Online]. Available: https://www.worldenergy.org/data/ resources/country/poland/coal/. [Accessed 299 2016].

[28] Dones R, Bauer C, Bolliger R, Burger B, Faist-Emmenegger M, Frischknecht R, Heck T, Jungbluth N, Röder A and Tuchschmid M. Ecoinvent Report: Life Cycle Inventories of Energy Systems: Results for Current Systems in Switzerland and Other UCTE Countries, Swiss Centre for Life Cycle Inventories, Dübendorf-Switzerland, 2007.

[29] Weisser D. A guide to life-cycle greenhouse gas (GHG) emissions from electric supply technologies, Energy, vol. 32, pp. 1543-1559, 2007.

[30] Turconi R, Boldrin A and Astrup A. Life cycle assessment (LCA) of electricity generation technologies: overview, compatilibity, and limitations, Renewable and Sustainable Energy Reviews, vol. 28, pp. 555-565, 2013.

[31] Dong Y, Gandhi N and Hauschild M. Development of ecotoxicity characterization factors for 14 metals (Al, Ba, Be, Cd, Co, Cr(III), Cs, $\mathrm{Cu}, \mathrm{Fe}(\mathrm{II}), \mathrm{Fe}(\mathrm{III}), \mathrm{Mn}, \mathrm{Ni}, \mathrm{Pb}, \mathrm{Sr}$ and $\mathrm{Zn}$ ) in freshwater, Chemosphere, vol. 112, pp. 26-33, 2014.

[32] The Nuclear Debate, World Nuclear Association, [Online]. Available: http://www.worldnuclear.org/info/Current-and-Future-Generation/The-Nuclear-Debate/. [Accessed 2411 2015].

[33] International Standard ISO 14043: Environmental management-life cycle assessment-life cycle interpretation, 2000. 